\title{
Studies on Genetic Divergence Analysis in Rice (Oryza sativa L.) under Sodic Soil
}

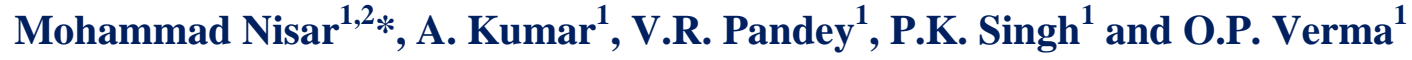 \\ ${ }^{1}$ Department of Genetics and Plant Breeding, Narendra Deva University of Agriculture and \\ Technology, Kumarganj, Faizabad-224229 (U.P.), India \\ ${ }^{2}$ Indian Institute of Pulses Reserch, Kalyanpur, Kanpur, U.P., India \\ *Corresponding author
}

\section{A B S T R A C T}

The valuable information through the Non-hierarchical Euclidean cluster analysis including one hundred four genotypes, were grouped in to eleven clusters, indicating the existence of high degree of genetic diversity in the germplasm collections evaluated under sodic soil $\left(\mathrm{pH}=9.2 ; \mathrm{EC}=2.21\right.$ of $\left.\mathrm{dS}^{\mathrm{m}-1} ; \mathrm{ESP}=45 \%\right)$. Analysis of variance revealed highly significant differences among germplasm collections indicating wide genetic variability in the existing genetic stock. The eleven clusters formed in divergence analysis contained genotypes of heterogeneous origin, thereby indicating non-parallelism between genetic and

\section{Keywords}

$\mathrm{D}^{2}$, Genetic divergence, Rice (Oryza sativa L.), Sodic soil.

Article Info

Accepted: 26 October 2017 Available Online: 10 December 2017 geographic diversity. In this context, cluster X, having single entry Kalanamak-Nitch, had very high inter-cluster distances from cluster III, IV, II, IX, VII and I. In addition, very high inter-cluster distances were also shown by cluster IX from cluster III, VII and VI, while cluster VIII exhibited high inter cluster distances from cluster III, II and I. The different clusters showed considerable differences in intra-cluster group means of eleven clusters and genotypes having distinctly different mean performance for various characters, were separated into different clusters. The lines belonging to diverse clusters and showing high mean performance in desirable direction for different traits, may be choosen as parents. In this context, the most promising genotypes for use as parents in hybridization programme were IR 26, Jagriti and Mehak of cluster I, NDRK 5095 and Pusa 33A of cluster II; NDRK 50039 and NDRK 50035 of cluster III and NDRK 50028, NDRK 50027, NDRK 50025 and IR-76346-3B-10-1-1-1 of cluster IV. Narendra Usar Dhan 3, NDRK 50034, Narendra Usar 2004 and Sarjoo 52 of cluster V; IR-72579-R-2R-13, Basmati Chandauli, Multan Basmati, Basmati Dehradoon, Kapoor Chinni and Dubraj Mirjapur of cluster VI; NDRK 5014, NDRK 5040, Sundri, Sugandhamati and NDRK 50030 of cluster VII and CSR 43, AGAMI-MI, NDRK 50032 and Johar of cluster VIII emerged as lines to be recommended for exploitation in hybridization programme to enhance the production and productivity of sodic soil.

\section{Introduction}

Rice (Oryza sativa L.) being the staple food for more than 70 per cent of our national population and source of livelihood for 120150 million rural households is backbone to the Indian Agriculture. According to the final estimate for the year 2014-15 by Ministry of Agriculture of India, the production of rice stood at 105.48 million tonnes (APDEA report, 2016). Soil salinity negatively affects agricultural production worldwide (FAO, 
2014). In India, 6.73 million hectare under salt affected area. (Mandal et al., 2009) Rice is the not only as a fundamental commodity and primary food source for more than half of the world's population, but also as emerges from the complex rice based ecosystems that influence issues of global concern such as food security and development. More than 90 per cent of the world's rice is grown and consumed in Asia, known as rice bowl of the world, where 60 per cent of the earth's people and two third of world's poor live (Khush and Virk, 2000). A large proportion of area under rice in our country is salt affected/sodic soil, but the potential for productivity gains in such areas has not been exploited. At present, however, most of the research is directed to irrigated and non-stress environments. While sustaining and increasing yields in irrigated and non-stress areas remains an important area of research, resources need to be shifted to emphasize on stress environments like sodic soils in the countries with a significant area of sodic soil such as India (Subaiah, 2006).

Although, the average productivity of rice is much lower in India than the average productivity at world level. The development of high yielding, widely adapted pureline rice varieties coupled with advances in production technology in past four decades has enabled us to come up with the demand of rice to a satisfactory level. However, rapidly increasing demand due to ever increasing Indian population has forced us to search for another quantum jump in rice production. The projection of India's rice production target for $2020 \mathrm{AD}$ is 120 million tonnes, which can be achieved only by increasing the rice production by over 2.0 million tones/year in the coming decade (Viraktamath and Shobha Rani, 2008). This has to be done through either improving health of problematic soil or develop stress free varieties under exploited stress environments. Thus, present investigation covered adoption of high yielding rice varieties to various stress environments and unutilized lands such as sodic soil would be an important strategy to meet this challenge. Salinity affects rice growth in varying degrees at all stages starting from germination to maturation (Manneh, 2004). The importance of genetic diversity in selecting parents to recover transgressive segregants has been repeatedly emphasized by many workers (Archana Devi et al., 2017). Non-hierarchical Euclidean cluster analysis and Mahalanobis' $\mathrm{D}^{2}$ analysis, serve as a most potential tool for classification, are a sort of multivariate analysis which helps the plant breeders in choosing suitable parents under tress situations for realizing superior segregants in breeding programmes.

Considering the wide importance of rice cultivation under salt affected environment, the present study was undertaken with the objective to access the genetic diversity of rice germplasm accessions and identification of better accessions for yield and yield attributing traits under sodic condition for sustainability.

\section{Materials and Methods}

The present investigation was carried out at Research Farm of Department of Genetics and Plant Breeding, N.D. University of Agriculture and Technology, Faizabad during Kharif, 2012. The climate of district Faizabad is semi-arid with hot summer and cold winter (sub-tropical) and the soil of the experimental site was partially reclaimed sodic soil $[\mathrm{ECe}=$ $\left.2.21\left(\mathrm{dS}^{\mathrm{m}-1}\right) ; \mathrm{pH}=9.2\right]$. In such a harsh environment an experiment of 100 germplasm lines along with four checks viz., Pokkali and Narendra Usar Dhan 3 (highly tolerant); Sarjoo 52 (moderately tolerant); and IR 28 (susceptible) were evaluated in augmented design (Federer, 1956). The experimental 
field was sub-divided in to 10 blocks of 14 plots each. The four checks were allocated randomly to four plots in each block, while remaining 10 plots in a block were used for accommodating the unreplicated test genotypes. The seeds were sown on 19 June, 2012 in separate pots and 28 days (17 July, 2012) old seedlings were transplanted in sodic soil as single seedling per hill in single row plots of $3 \mathrm{~m}$ length following $20 \mathrm{~cm}$ inter-row and $15 \mathrm{~cm}$ intra-row spacing. All the recommended cultural practices were followed to raise a good crop. The fertilizers were applied @ $120 \mathrm{~kg}$ nitrogen, $60 \mathrm{~kg}$ phosphorus and $60 \mathrm{~kg}$ potash per hectare through urea, DAP and murate of potash, respectively. The mean data recorded for all the characters studied were days to $50 \%$ flowering, days to maturity, plant height, effective tillers per plant, panicle length $(\mathrm{cm})$, spikelets per panicle and spikelet fertility (\%), 1000-grain weight $(\mathrm{g})$, biological yield per plant $(\mathrm{g})$, harvest index $(\%)$ and grain yield per plant (g). Non-hierarchical Euclidean Cluster analysis (Beale, 1969; Spark, 1973) was used to examine genetic divergence existing in rice genotypes evaluated.

\section{Results and Discussion}

The analysis of variance revealed highly significant differences among traits under sodic soil. The mean performance of 100 rice genotypes and four checks for 11 characters revealed very wide range of variation in mean performance of genotypes for all the characters under study. The comparison of mean performance of 104 entries for 11 traits possessing significant differences, revealed existence of very high level of variability in the germplasm collections evaluated in the present study. The Non- hierarchical Euclidean cluster analysis was employed to study the genetic diversity (Table 1,2 and 3). The pseudo F-test revealed that 11 cluster arrangements were most appropriate for grouping the 104 genotypes without over lapping clusters.

The discrimination of germplasm lines in to so many discrete clusters suggested presence of high degree of genetic diversity in the material evaluated. Earlier workers have also reported substantial genetic divergence in the rice materials. Presence of substantial genetic diversity among the germplasm lines screened in the present study indicated that this material may serve as good source for selecting the diverse parents for hybridization programme aimed at isolating desirable segregants for grain yield and other important characters. More ever, selection and choice of parents mainly depends upon contribution of characters towards divergence also reported by Nayak et al., (2004), Baradhan and Thangavel (2011), Kumar et al., (2013) and Krishnamurthy et al., (2017).

An examination of the clustering pattern of the 104 rice genotypes in to eleven clusters revealed that the genotypes of heterogeneous origin were frequently present in same cluster. Although the genotypes originated in same place or geographic region were also found to be grouped together in same cluster, the instances of grouping of genotypes of different origin or geographical regions in same cluster were observed in case of all the clusters except the single entry cluster $\mathrm{X}$. This indicated lack of any definite relationship or correlation between genetic diversity and geographic origin of the rice genotypes evaluated in the present study. Therefore, the selection of parental material for hybridization programme simply based on geographic diversity may not be rewarding exercise (Krishnamurthy et al., 2017). The choice of suitable diverse parents based on genetic divergence analysis would be more fruitful than the choice made on the basis of geographical distances. This finding is in conformity with the previous reports 
advocating lack of parallelism between genetic and geographic diversity in rice. Cheema et al., (2004) advocated that the number of clusters formed, number of genotypes in the clusters and superposition of the genotypes within the clusters indicated the possibility of genetic improvement for yield and yield components. Among the eleven clusters, cluster VI was largest group consisting of sixteen genotypes, followed by cluster IV having fourteen entries. Cluster II and VII had 12 entries each, while clusters V, I, XI and IX possessed 11,10,9 and 8 genotypes, respectively. Cluster III had seven entries and cluster VIII was constituted by four genotypes. Cluster X having only one genotype, Kalanamak-Nitch was the smallest and monogenotypic cluster.

Table.1 Clustering pattern of 104 rice genotypes on the basis of non-hierarchical Euclidean cluster analysis of 11 characters

\begin{tabular}{|c|c|l|}
\hline $\begin{array}{c}\text { Cluster } \\
\text { No. }\end{array}$ & $\begin{array}{c}\text { Number of } \\
\text { genotypes }\end{array}$ & \multicolumn{1}{|c|}{ Genotypes } \\
\hline I & $\mathbf{1 0}$ & $\begin{array}{l}\text { IR 74095-AC-64, IR 21-2-9-B-1-5, IR 26, Dhulaniya., NDRK 50036, Lalpari No.3, Getu, Jagriti, NDRK } \\
50029, \text { Mehak }\end{array}$ \\
\hline II & $\mathbf{1 2}$ & $\begin{array}{l}\text { NDRK 5004, NDRK 50004, Jaya, NDRK 50023, Lal Kahwa, Y 134, PSBRC 90, NDRK 5095, NDRK } \\
\text { 5093, NDRK 50038, Pusa 33A, Kastauri Chandauli }\end{array}$ \\
\hline III & $\mathbf{7}$ & $\begin{array}{l}\text { IR 77664-B-25-1-2-1-3-12 AJY 1, NDRK 50037, Sabarmati Raibareli, NDRK 50039, NDRK 50035, IR 28 } \\
\text { (C), Raghubansi }\end{array}$ \\
\hline IV & $\mathbf{1 4}$ & $\begin{array}{l}\text { NDRK 5012, NDRK 50026, NDRK 5022, IR 76346-3B-10-1-1-1, NDRK 50027, NDRK 5097, NDRK } \\
\text { 50021, NDRK 50028, NDRK 50025, Nagina 22, Moongphali D, Beni Bhog, NDRK 50024, CSR 10 }\end{array}$ \\
\hline V & $\mathbf{1 1}$ & $\begin{array}{l}\text { NDRK 5019, Narendra Usar-2009, NDRK 50031, NDRK 50033, NDRK 50005, Pokkali (C), } \\
\text { NarendraUsar Dhan 3 (C), Sarjoo 52 (C), NDRK 50034, Shyam Jeera, NDRK 50003 }\end{array}$ \\
\hline VI & $\mathbf{1 6}$ & $\begin{array}{l}\text { IR 72579-R-2R-1-3, Basmati Deharadoon, Tilak Chandan, Pakistani Basmati, Kapoor Chini, Sonali, Pusa } \\
\text { 33, Basmati Hariyana, Pusa Basmati, Basmati 370, Basmati Kota, Basmati A, Multan Basmati, Lalmati } \\
\text { Tanda, Dubraj Mirjapur, Basmati Chandauli }\end{array}$ \\
\hline VII & $\mathbf{1 2}$ & $\begin{array}{l}\text { NDRK 5081, NDRK 50030, IR71833-3R-3-2-1-B, NDRK 50019, MTU-20-1-1, Sundri, Sugandhmati, IR } \\
\text { 5931-110-1, NDRK 5014, NDRK 5040, Panvel-1, CSR 90-IR2 }\end{array}$ \\
\hline VIII & $\mathbf{4}$ & NDRK 50032, AGAMI-MI, Johar, CSR 43 \\
\hline IX & $\mathbf{8}$ & CSRC (S) 52-1-1, NDR 6279, NDR 6241, Sita Bhog, Nona Bokra, NDR 6240, Laung Choor, Dhania A \\
\hline $\mathbf{X}$ & $\mathbf{1}$ & Kalanamak-Nitch \\
\hline XI & $\mathbf{9}$ & $\begin{array}{l}\text { Malasiya, Sona Choor, Bindli, Tulsi Manjari, Kalanamak-3, Dulha Bhog, Karnol Local A, NDR 6242, } \\
\text { Deharadoon Basmati }\end{array}$ \\
\hline
\end{tabular}

Table.2 Estimate of average intra and inter-cluster distances for 11 clusters in rice germplasm

\begin{tabular}{|c|c|c|c|c|c|c|c|c|c|c|c|}
\hline $\begin{array}{c}\text { Cluster } \\
\text { number }\end{array}$ & I & II & III & IV & V & VI & VII & VIII & IX & X & XI \\
\hline I & $\mathbf{7 . 4 5 4}$ & 12.742 & 12.889 & 19.549 & 13.41 & 21.232 & 22.569 & 38.239 & 28.130 & 47.552 & 23.286 \\
\hline II & & $\mathbf{8 . 1 7 6}$ & 11.635 & 13.019 & 16.427 & 22.224 & 20.026 & 39.485 & 34.956 & 67.455 & 30.355 \\
\hline III & & & $\mathbf{4 . 5 4 6}$ & 13.043 & 13.34 & 24.919 & 22.306 & 42.532 & 44.110 & 76.582 & 36.486 \\
\hline IV & & & & $\mathbf{9 . 0 5 8}$ & 14.529 & 23.891 & 17.229 & 26.233 & 34.557 & 72.988 & 29.964 \\
\hline V & & & & & $\mathbf{8 . 1 0 2}$ & 17.458 & 19.138 & 25.416 & 32.323 & 57.106 & 24.836 \\
\hline VI & & & & & & $\mathbf{9 . 1 6 6}$ & 17.648 & 30.499 & 35.072 & 55.056 & 19.742 \\
\hline VII & & & & & & & $\mathbf{1 2 . 3 3 0}$ & 23.747 & 35.835 & 64.716 & 23.036 \\
\hline VIII & & & & & & & $\mathbf{1 5 . 8 0 6}$ & 32.460 & 65.641 & 25.394 \\
\hline IX & & & & & & & & & $\mathbf{1 4 . 0 9 0}$ & 29.245 & 15.436 \\
\hline X & & & & & & & & & & $\mathbf{0 . 0 0 0}$ & 28.039 \\
\hline XI & & & & & & & & & & & $\mathbf{9 . 0 2 3}$ \\
\hline
\end{tabular}

Bold figures indicate the intra-cluster distance 
Table.3 Cluster means for 11 characters of rice germplasm

\begin{tabular}{|c|c|c|c|c|c|c|c|c|c|c|c|}
\hline $\begin{array}{c}\text { Cluster } \\
\text { number }\end{array}$ & $\begin{array}{c}\text { Days to } \\
\mathbf{5 0 \%} \\
\text { flowering }\end{array}$ & $\begin{array}{c}\text { Days to } \\
\text { maturity }\end{array}$ & $\begin{array}{c}\text { Plant } \\
\text { height } \\
\mathbf{( c m})\end{array}$ & $\begin{array}{c}\text { Effective } \\
\text { tillers/ } \\
\text { plant }\end{array}$ & $\begin{array}{c}\text { Panicle } \\
\text { longth } \\
(\mathbf{c m})\end{array}$ & $\begin{array}{c}\text { Spikelets/ } \\
\text { panicle }\end{array}$ & $\begin{array}{c}\text { Spikelet } \\
\text { fertility } \\
(\boldsymbol{\%})\end{array}$ & $\begin{array}{c}\mathbf{1 0 0 0}- \\
\text { grain } \\
\text { weight } \\
(\mathbf{g})\end{array}$ & $\begin{array}{c}\text { Biological } \\
\text { yield/ plant } \\
(\mathbf{g})\end{array}$ & $\begin{array}{c}\text { Harvest } \\
\text { index } \\
(\%)\end{array}$ & $\begin{array}{c}\text { Grain } \\
\text { yield/ } \\
\text { plant } \\
(\mathbf{g})\end{array}$ \\
\hline I & 99.15 & 127.25 & 98.20 & 6.40 & 25.30 & 138.47 & 80.99 & 22.91 & 32.67 & 35.90 & 11.71 \\
\hline II & 87.64 & 115.87 & 106.32 & 7.01 & 24.40 & 99.07 & 86.76 & 26.38 & 30.95 & 36.00 & 10.98 \\
\hline III & 86.21 & 114.81 & 104.24 & 7.02 & 25.31 & 91.82 & 81.30 & 27.87 & 26.50 & 43.70 & 11.70 \\
\hline IV & 86.98 & 115.41 & 109.27 & 8.75 & 23.85 & 115.78 & 88.62 & 27.08 & 36.54 & 43.02 & 15.76 \\
\hline V & 92.28 & 121.17 & 122.19 & 6.19 & 25.61 & 175.12 & 83.31 & 27.06 & 37.08 & 41.95 & 15.65 \\
\hline VI & 88.04 & 116.54 & 153.02 & 7.54 & 30.64 & 140.25 & 83.76 & 22.64 & 48.23 & 35.48 & 17.17 \\
\hline VII & 88.10 & 116.83 & 117.82 & 10.93 & 27.05 & 124.79 & 85.01 & 28.94 & 51.87 & 36.72 & 19.03 \\
\hline VIII & 96.04 & 124.83 & 115.19 & 9.75 & 24.57 & 198.47 & 89.00 & 24.28 & 62.88 & 42.20 & 26.34 \\
\hline IX & 121.94 & 150.67 & 123.74 & 8.32 & 21.35 & 147.06 & 87.48 & 14.41 & 50.96 & 35.44 & 17.89 \\
\hline X & 154.60 & 182.95 & 144.06 & 10.17 & 28.72 & 206.33 & 83.50 & 15.64 & 40.11 & 31.18 & 13.04 \\
\hline XI & 115.99 & 144.59 & 134.53 & 8.59 & 26.81 & 135.55 & 84.83 & 18.65 & 57.31 & 34.70 & 20.23 \\
\hline
\end{tabular}

The estimates of average intra and intercluster distances for eleven clusters, revealed that the genotypes present in a cluster had little genetic divergence from each other with respect to aggregate effect of 11 characters under study, while much more genetic diversity was observed between the genotypes belonging to different clusters (Table 2). Since, high or optimum genetic divergence is desired between the parents of hybridization plan for obtaining higher frequency of desirable recombinants, the chances of obtaining good segregants by crossing the little diverse genotypes belonging to same cluster are very low. In order to increase the possibility of isolating good segregants in the segregating generations, it would be logical to attempt crosses between the diverse genotypes belonging to clusters separated by large inter cluster distances. In the present investigation, cluster $\mathrm{X}$, constituted by single entry, (Kalanamak-Nitch) which showed highest inter-cluster distance from cluster III (76.582), besides having very high intercluster distances from cluster IV (72.988), II (67.455), VIII (65.641), VII (64.716), V (57.106), VI (55.056) and cluster I (47.552). High inter-cluster distances were also shown by cluster IX from cluster III (44.110), VII (35.835) and VI (35.072). Similarly, cluster
VIII recorded high order inter-cluster distances from cluster III (42.532), II (39.485) and I (38.239). Thus, crossing between the genotypes belonging to above mentioned cluster pairs is recommended for developing high yielding rice genotypes for sodic soil conditions. The lowest inter cluster distance was observed between cluster II and III (11.635), followed by cluster I and II (12.742), cluster II, IV (13.091), cluster III and IV (13.043). This indicated that the hybridization between the genotypes of above four cluster pairs having very low intercluster distances may not be rewarding owing to little genetic diversity among their genotypes. These findings are similar to those of Baradhan and Thangavel (2011), Kumar and Verma (2015).

The cluster means for each of the eleven characters for eleven clusters revealed that monogenotypic (Kalanamak-Nitch) cluster X had desirable highest cluster means for spikelets per panicle and second highest cluster means for panicle length and effective tillers per plant (Table-3). Cluster X showed very high inter-cluster distances from cluster III, IV, II, VIII, VII, V, VI and I. Crossing of Kalanamak-Nitch with promising lines of the above mentioned eight cluster appears useful 
to yield desirable segregants. Cluster IX with eight entries showed undesirable lowest cluster means for panicle length and 1000grain weight following second highest cluster means for days to $50 \%$ flowering and days to maturity. Cluster IX and X had undesirable high means for late flowering and late maturity along with low to moderate means for most of the characters. Cluster XI having nine genotypes showed second highest cluster means for grain yield and biological yield per plant, possessing moderate performance for most of the characters except undesirable second lowest cluster means for harvest index. Cluster VIII with four genotypes (NDRK 50032, AGAMI-MI, Johar and CSR 43) recorded desirable highest cluster means for grain yield per plant, biological yield per plant and spikelet fertility following second highest mean for spikelets per panicle, possessing desirable means for remaining characters. Among the clusters showing high inter cluster distances from cluster X, IX and VIII, cluster III was most important and common for all three clusters. Cluster III with seven genotypes exhibited desirable lowest cluster means for days to 50\% flowering and days to maturity, while highest cluster mean for harvest index, second highest cluster mean for 1000-grain weight and second lowest cluster mean for plant height but this cluster had undesirable lowest cluster mean for spikelets per panicle and biological yield per plant and second lowest cluster means for grain yield per plant and spikelets fertility. Cluster II, with twelve genotypes, showed undesirable lowest cluster means for grain yield per plant and second lowest cluster mean for biological yield per plant and spikelets per panicle. Cluster I with ten genotypes showed undesirable lowest cluster mean for spikelet fertility and second lowest cluster mean for effective tillers per plant, besides having desirable lowest cluster mean for plant height. In general, entries of cluster I, II and III were characterized by early flowering, early maturity and short stature but had low mean performances for grain yield and most of its components. Cluster VII with twelve genotypes had highest cluster mean for 1000-grain weight and effective tillers per plant, besides having moderate to high means in desirable direction for remaining characters. Similarly, cluster VI showed highest cluster means for panicle length and plant height. Cluster V had lowest cluster means for effective tillers per plant and moderate cluster means for remaining characters. Cluster IV with fourteen genotypes recorded desirable second highest cluster means for harvest index and spikelet fertility and second lowest means for days to $50 \%$ flowering and days to maturity but it had undesirable second lowest cluster mean for panicle length. Entries of cluster VI, V and IV were characterized by moderate mean performance for grain yield and most of its components.

Perusal of the discussion clearly shows wide variation from one cluster to another in respect of cluster means for eleven characters, which indicated that genotypes having distinctly different mean performance for various characters were separated into different clusters. The crossing between the entries belonging to cluster pairs having large inter cluster distance and possessing high cluster means for one or other characters to be improved may be recommended for isolating desirable recombinants in the segregating generations in rice. However, caution should be exercised in selecting very diverse genotypes, because the frequency of heterotic crosses and magnitude of heterosis for yield and its components were found to be higher in crosses between parents with intermediate divergence than the extreme one. The selection on diverse parents for hybridization programme should be done after considering the inter-cluster distances and mean performance of genotypes for different 
characters. The lines belonging to diverse clusters and showing high mean performance in desirable direction for different traits may be choosen as parents. In this context, the most promising genotypes for use as parents in hybridization programme were IR 26, Jagriti and Mehak of cluster I, NDRK 5095 and Pusa 33A of cluster II; NDRK 50039 and NDRK 50035 of cluster III and NDRK 50028, NDRK 50027, NDRK 50025 and IR76346-3B-10-1-1-1 of cluster IV. Narendra Usar Dhan 3, NDRK 50034, Narendra Usar 2004 and Sarjoo 52 of cluster V; IR-72579-R2R-1-3, Basmati Chandauli, Multan Basmati, Basmati Dehradoon, Kapoor Chinni and Dubraj Mirjapur of cluster VI; NDRK 5014, NDRK 5040, Sundri, Sugandhamati and NDRK 50030 of cluster VII and CSR 43, AGAMI-MI, NDRK 50032 and Johar of cluster VIII emerged as lines to be recommended for exploitation in hybridization programme. Similarly, desirable lines were NDR 6241, Nona Bokra, Sita Bhog, Dhania A, Laung Choor and NDR 6240 of cluster XI; Kalanamak Nitch of clusterX and NDRK 6242, Dehradoon Basmati and Bindli of cluster XI appreared as potential parents for hybridization programme in order to get desirable transgressive segregants of grain quality traits of rice (Vishwakarma et al., 2003; Verma et al., 2006; Tiwari and Jatav, 2014; Kumar and Verma, 2015).

The genotypes identified above as promising diverse parents are recommended to be crossed with the genotypes belonging to clusters separated by high inter-cluster distances from their clusters. Thus, Kalanamak Nitch of cluster X may be crossed with promising genotypes identified from cluster III, IV, II, VIII, VII, VI, V and I. Similarly, promising lines of cluster VIII should be hybridized with those of III, II and I while desirable genotypes of IX merit hybridization with those of cluster III, VII and
VI to sustain the production and productivity of rice under sodic soil. These findings corroborate the results of Vijayalakshmi et al., (2008), Viraktamath and Shobha Rani (2008) and Wei et al., (2004). Some genotypes may perform well under salinity but not under alkalinity and vice-versa and some perform well under both stresses. This implies that the genotypes may show specific adoption to saline and alkaline conditions by virtue of different combinations of mechanism/genes governing their tolerance (Krishnamurthy et al., 2017).

\section{Acknowledgement}

The authors are thankful to Dr. P.K. Singh, Professor and Head of the Department of Genetics and Plant Breeding, N.D. University of Agril and Technology, Kumarganj Faizabad, for providing help and encouragement during this study.

\section{References}

Arunachalam, V. 1981. Genetic distance in plant breeding. Indian J. Genet. 41(2): 226-236.

Baradhan, G. and Thangavel, P. 2011. D2 analysis in rice (Oryza sativa L.). Plant Archives. 11(1): 373-375.

Beale E.M.L. 1969. Euclidean Cluster Analysis. Bull Int. State Inst. 43: 92-94

Cheema, A. A., Rashid, M., Ashraf, M. and Qamar, Z. U. 2004. Genetic divergence in rice collections. Pak. J. Bot. 36(3): 557566.

Devi A., Kumari P., Dwivedi R., Dwivedi S., Verma O.P., Singh P.K. and Dwivedi D.K. 2017. Gene action and combining ability analysis for yield and yield contributing traits in rice (Oryza sativa L.) over environment. J. Pharmacognosy and Phytochemistry, 6(3): 662-671.

FAO, Extent of salt affected soils. www.fao.org/soils-portal/soil-managementof-some problem-soil/salt-affected soils/ more-information-on-saltaffected-soils/en (Dec-2014). 
Federer, W. T. 1956. Augmented Designs. Hawaii Planters' Record LV. 2: 191-208.

Jatasara, D.S. and Paroda, R.S. 1983. Genetic divergence in wheat. Indian J. Genet. 43: 63-67.

Khush, G.S. and Virk, P.S. 2000. Rice breeding achievements and future strategies. Crop Improvemt. 27(2): 115-144.

Krishnamurthy, S.L., Sharma, P.C., Sharma, D.K., Ravikiran, K.T., Singh, Y.P., Mishra, V.K., Burman, D., Maji, B., Mandal, S., Sarangi, S.K., Gautam,

Kumar, A. and Verma, O.P. 2015. Correlation and path coefficient analysis in certain quantitative traits in rice (Oryza sativa $\mathrm{L}$.) under saline-alkaline conditions. Res. Envi. Life Sci. 8(3): 443-446.

Kumar, A., Rangare, N. R. and Vidyapati V. 2013. Study of genetic variability of indian and exotic rice germplasm in allahabad agroclimate. The bioscan 8(4): 1445-1451.

Mandal, A.K., Sharma, R.C. and Singh, G.B. 2004. Assessment of salt affected soils in India using GIS. Geocarto Int. 24(6): 437456.

Manneh, B. 2004. Genetic, physiological and modelling approaches towards tolerance to salinity and low nitrogen supply in rice (Oryza sativa L.). Wageningen Universiteit.

Nayak, A. R., Chaudhury, D. and Reddy, J. N. 2004. Genetic divergence in scented rice. Oryza. 41(384): 79-82.

Singh R.K., Manohara P.K., Marandi K.K., Padamavathi B.C., Vanve G., Patil P.B, Thirumeni K.D., Verma S., Khan O.P., Tiwari A.H, Geetha S., Shakila S., Gill M., Yadav R., Roy, V.K., Prakash S.K.B., Bonifacio M., Abdelbagi J., Smail I., Gregorio, G.B., and Singh R.K. 2017.
Identification of mega-environments and rice genotypes for general and specific adaptation to saline and alkaline stresses in India. Scientific Reports. 7:7968 (1-14): DOI : 10, 1038/541598-017-08532-7.

Spark, D.N. 1973. Euclidean cluster analysis. Algorithm As. 58. Appl. Statist. 22: 126130.

Subaiah, S.V. 2006. Several options being tapped. The Hindu Survey of Indin Agriculture, pp. 50-54.

Tiwari, G.C., Jatav, N.K., 2014. Combining ability analysis for grain yield and its related characters in rice. Trends in Biosciences: 7(13): 1444-1448.

Verma, O.P., Singh, R.V., Dwivedi, J.L. and Prakash, N., 2006. Genetic analysis of yield and its components in rice. Oryza. 43(1): 55-57.

Vijayalakshmi, B., Vijay, D., Raju, P.R.K. and Satyanarayana, P.V. 2008. Genetic divergence of qualitative and quantitative characters in lowland rice germplasm. Crop Research (Hisar), 36(1/3: 212-214.

Viraktamath, B.C. and Shobha Rani, N. 2008. Rice : Pivotal position achieved by combination of factors. The Hindu Survey of Indian Agriculture, pp. 22-24.

Vishwakarma, D.N., Vishwakarma, S.R., Verma, L.P. and Prasad K. 2003. Combining ability analysis of some quantitative characters in rice. Ann. Pl. Soil. Res., B5(1); 72-75.

Wei, L., Chao, L.Z., Li, W.M.H., Jian, W. and Liang, Z.H. 2004. Heterotic ecotypes grouping of japonica rice by combining ability. Acta Agronomica Sinica, 30(1): 6672.

\section{How to cite this article:}

Mohammad Nisar, A. Kumar, V.R. Pandey, P.K. Singh and Verma. O.P. 2017. Studies on Genetic Divergence Analysis in Rice (Oryza sativa L.) under Sodic Soil. Int.J.Curr.Microbiol.App.Sci. 6(12): 3351-3358. doi: https://doi.org/10.20546/ijcmas.2017.612.390 